\title{
Online Spatial Cancer Registry System for Nigeria
}

\author{
Adebayo Peter Idowu ${ }^{1}$, Kehinde Oladipo Williams ${ }^{2}$, Bunmi Alonge ${ }^{1}$ and Olusegun Ajibola Sarumi ${ }^{1}$ \\ ${ }^{1}$ Department of Computer Science \& Engineering, Obafemi Awolowo University, Ile-Ife, Nigeria \\ ${ }^{2}$ Department of Physical and Computer Sciences, College of Natural and Applied Sciences, McPherson \\ University, Ajebo, Ogun State, Nigeria \\ kehindewilliams@yahoo.com; paidowu1@yahoo.com
}

\begin{abstract}
Cancer has become a major source of morbidity and mortality globally. The incidence of cancer is rising as well as in Nigeria as it continues to eat deep into the nation claiming lives of both prominent and less prominent citizens of the country. This disease is increasingly taking the lives of productive citizens thereby adding to the poverty level of the nation. In this paper, we present a system which was developed for population based cancer registry in Nigeria. This system is an online system with spatial features.

The online spatial cancer registry for Nigeria was developed using Adobe Dreamweaver and Notepad++ as the Integrated Development Environments, HTML, CSS and JavaScript were used for the frontend, PHP was used as the scripting language, and MySQL with google map. The software used were open source which ensured that the application would be robust, reusable, cheap and highly scalable.

The result of the developed system shows that health officers, policy makers and all other authorized stakeholders would be able to register, login, and run queries on information that has been previously entered into the system. With the system, the spatial distribution of cancer in any location in Nigeria can be easily visualized and query. Policy makers and authorized users would be able to visualize and query the system in order to take appropriate steps in addressing cancer in Nigeria.

In conclusion, this system will help create national database for cancer patients and be able to analyse the spatial distribution of cancer and the system is user-friendly.
\end{abstract}

Keywords: Cancer, Registry, Spatial, Online, Open Source

\section{Introduction}

Cancer is a group of diseases characterized by unregulated division and spread of cells. The cancerous cells may occur in liquids, as in leukaemia (American Cancer Society, 2008). Most cancer, however, occur in solid tumours that originally appear in various tissues in various parts of the body. By their original locations they are classified into various types of cancer, such as lung, colon, breast, prostate cancer, etc. Localized tumours can be removed by surgery or irradiation with high survival rates. As cancer progresses, however, it metastasizes - invading the surrounding tissues, entering the blood stream, spreading and establishing colonies in distant parts of the body (American Cancer Society, 2008). Only a third of patients with metastasized cancer survive more than five years. Invasive distensions spreading crab-like from a 
Adebayo Peter Idowu, Kehinde Oladipo Williams, Bunmi Alonge and Olusegun Ajibola Sarumi; Online Spatial Cancer Registry System for Nigeria. Journal of Biomedical Engineering and Medical Imaging, Volume 2, No 5, October (2015) , pp 10-20

tumour in the breast were described by Hippocrates. From the crab, karkinos in Greek and cancer in Latin, came the name of the disease and the name of its inducing agents, carcinogens (Dervan, 1999).

In 2007, there were 11 million cancer cases, 7 million cancer deaths and 25 million people living with cancer. This is projected to increase to 27 million cases, 17 million deaths and 75million people living with cancer in 2050 (World Health Organisation, 2006). Cancer is a leading cause of disease worldwide. An estimated 14.1 million new cancer cases occurred in 2012. Lung, female breast, colorectal and stomach cancers accounted for more than $40 \%$ of all cases diagnosed worldwide. In men, lung cancer was the most common cancer (16.7\% of all new cases in men). Breast cancer was by far the most common cancer diagnosed in women (25.2\% of all new cases in women) (World Cancer Factsheet, 2014). Cancer is a leading cause of death worldwide, with 8.2 million deaths in 2012. More than half of all cancer deaths each year are due to lung, stomach, liver, colorectal and female breast cancers (World Cancer Factsheet, 2014).

Cancer is a major public health burden in both developed and developing countries. It is the second largest common disease spread world-wide (Kainsa et al., 2012). When a cell is damaged or altered without repair to its system, it usually dies. But if such damaged or unrepaired cells do not die and proliferate with uncontrolled growth; a mass of cancer cells develop. Cancer has a complex aetiology with multiple risk factors that involve the interplay between genetic and environmental influences. The redox dysregulation originates from metabolic alterations and it is dependent on mitogenic and survival signalling through reactive oxygen species. There is a delicate balance between the production and the destruction of reactive species; for this, we need to understand the role of redox homeostasis in cancer. So, the specific vulnerability of the malignant cells can be selectively targeted (Dawane and Pandit, 2012).

A cancer registry is an information system designed for the collection, management and analysis of data on persons with the diagnosis of a malignant or neoplastic disease (National Cancer Registry Association, 2014). Hospital-based cancer registries which are also referred to as Health care institution registries are concerned with the recording of information on the cancer patients seen in a particular hospital, maintain data on all patients diagnosed and/or treated for cancer at their facility. Population-based cancer registries also known as Central Registries seek to collect data on all new cases of cancer occurring in a well defined population, maintain data on all cancer patients within certain geographical areas. Special purpose registries maintain data on a particular type of cancer, such as brain tumours. Maintaining a Cancer Registry ensures that health officials have accurate and timely information, while ensuring the availability of data for treatment, research, and educational purposes.

The aim of this paper is to develop an online cancer registry for Nigeria with spatial feature. This spatially captures cases of cancer in the hospitals and stores information about the cases of cancer and type of cancer in any location in Nigeria. This system can be used by health officers and policy makers to know the distribution of each type of cancer in any location in Nigeria and this will allow them to take appropriate policy that will handle the health challenge. It will also make them to know type of cancer peculiar to each location and aid in querying why such cancer is paramount in the location.

\section{Cancer in Nigeria}

The burden of cancer in Nigeria is unknown; mainly because of lack of statistics or under-reporting. This is not peculiar to only Nigeria but most parts of Africa. In a study of cancer registry literature update from 
all over the world, only $1 \%$ of the literature emanated from Africa compared to $34 \%$ and $42 \%$ from Europe and Asia respectively. This is partly due to inaccurate population statistics which makes age specific incidence rates impossible or if available inaccurate (World Health organisation, 2008).

Annually, there are about 100,000 new cancer cases in Nigeria, this is estimated to increase to 500,000 in 2010. It was estimated that incidence of cancer in Nigerian men and women by 2020 will be $90.7 / 100,000$ and $100.9 / 100,000$ and the deaths rates will be $72.7 / 100,000$ and $76,000 / 100,000$, respectively (World Health organisation, 2008).

Cancer currently accounts for $4.4 \%$ of all deaths and is likely to increase to $6.8 \%$ in 2030 (World Health organisation, 2008). Out of 89,000 cancer deaths in $2005 ; 54,000$ of these were younger than 70 years. The commonest cancers of Nigerian men are cancers of prostate, liver and lymphomas (Parkin, 2003; Awodele et al., 2011). In the women, cancer of cervix and breasts are commonest with minimal regional variation.

The Ibadan cancer registry showed a reduction in age standardized mortality rate from 1960 to 1999 . This was attributed to introduction of user fees and reduction in the coverage area. While cervical cancer is commonest in Zaria, Northern Nigeria (Abioye, 198) as in rest of Africa (Ngoma, 2006), breast cancer has become the commonest cancer of women in Ibadan, Southern Nigeria (Awodele et al., 2011; Parkin, 2003). These common cancers should be the focus of cancer control programs in Nigeria.

Moreover, due to the epidemiological shift, increase in ageing population, high rate of infections and entrenchment of the modifiable risk factors, cancers will yet pose significant challenge to Nigeria and other developing countries which currently lack cancer control programs directed at reducing cancer incidence and mortality and to improve quality of life. There are very few human and material resources for cancer control in developing countries where cancers occur at younger ages, $70 \%$ of cancer deaths occur and only $5 \%$ of global funds for cancer control is present (World Health Organisation, 2002).

Large proportions of the population still never seek orthodox medical care and so are not recorded. Other reasons are inadequate diagnostic facilities, limited access to care, inadequate technical manpower and infrastructure as well as quality of cancer data systems all contribute to inaccurate data on cancer burden.

\section{Related Literature}

Cancer is a public health problem worldwide affecting all categories of persons. Cancer is a major public health burden in both developed and developing countries. It is the second largest common disease spread world-wide (Kainsa et al., 2012). It is the second common cause of death in developed countries and among the three leading causes of death in developing countries (World Health Organisation, 2005).

Cancer is a leading cause of disease worldwide. It is the second most common cause of death; constituting $12 \%$ of all deaths after cardiovascular disease. It kills more people than Tuberculosis, HIV/AIDS and Malaria combined (World Health Organisation, 2006). In 2007, there were 11 million cancer cases, 7 million cancer deaths and 25 million people living with cancer. This is projected to increase to 27 million cases, 17 million deaths and 75million people living with cancer in 2050 (World Health Organisation, 2008).

An estimated 14.1 million new cancer cases occurred in 2012. Lung, female breast, colorectal and stomach cancers accounted for more than $40 \%$ of all cases diagnosed worldwide. In men, lung cancer was the most 
Adebayo Peter Idowu, Kehinde Oladipo Williams, Bunmi Alonge and Olusegun Ajibola Sarumi; Online Spatial Cancer Registry System for Nigeria. Journal of Biomedical Engineering and Medical Imaging, Volume 2, No 5, October (2015) , pp 10-20

common cancer ( $16.7 \%$ of all new cases in men). Breast cancer was by far the most common cancer diagnosed in women (25.2\% of all new cases in women) (World cancer factsheet, 2014). Cancer is a leading cause of death worldwide, with 8.2 million deaths in 2012. More than half of all cancer deaths each year are due to lung, stomach, liver, colorectal and female breast cancers (World Cancer Factsheet, 2014). Approximately $44 \%$ of cancer cases and $53 \%$ of cancer deaths occur in countries at a low or medium level of the Human Development Index (HDI) (World Cancer Factsheet, 2014).

Liver cancer in men is the fifth most frequently diagnosed cancer worldwide but the second most frequent cause of cancer death. In women, it is the seventh most commonly diagnosed cancer and the sixth leading cause of cancer death. An estimated 748,300 new liver cancer cases and 695,900 cancer deaths occurred worldwide in 2008. Half of these cases and deaths were estimated to occur in China. Globally, rates are more than twice as high in males as in females. The highest liver cancer rates are found in East and SouthEast Asia and in Middle and Western Africa, whereas rates are low in South-Central and Western Asia, as well as Northern and Eastern Europe (World Cancer Factsheet, 2014).

If recent trends in major cancers are seen globally in the future, the burden of cancer will increase to 23.6 million new cases each year by 2030. This represents an increase of $68 \%$ compared with 2012 (66\% in low and medium HDI countries and 56\% in high and very high HDI countries) (World cancer factsheet, 2014).

Cancer is an emerging public health problem in Africa. According to the International Agency for Research on Cancer (IARC), about 681,000 new cancer cases and 512,400 cancer deaths occurred in 2008 in Africa. These numbers are projected to nearly double (1.28 million new cancer cases and 970,000 cancer deaths) by 2030 simply due to the aging and growth of the population, with the potential to be even higher because of the adoption of behaviours associated with western lifestyles, such as smoking, unhealthy diet, and physical inactivity (International Agency for Research on Cancer, 2014). Despite this growing burden, cancer continues to receive low public health priority in Africa, largely because of limited resources and other pressing public health problems, including communicable diseases such as acquired immune deficiency syndrome (AIDS)/human immunodeficiency virus (HIV) infection, malaria, and tuberculosis. It may also be in part due to a lack of awareness about the magnitude of the current and future cancer burden among policy-makers, the general public, and international private or public health agencies interested in global health.

Cancers related to infectious agents (cervix, liver, Kaposi sarcoma, urinary bladder) are among the dominant forms of cancer in Africa. In 2008, cervical cancer accounted for $21 \%$ of the total newly diagnosed cancers in females and liver cancer for $11 \%$ of the total cancer cases in males (International Agency for Research on Cancer, 2014; America Cancer Society, 2014). Parkin et al (2008) reported that in indigenous Africans, 650,000 people of estimated 965million are diagnosed of cancer annually and lifetime risk of dying from cancer in African women is 2 times higher than in developed countries.

Africa carries an increasing cancer burden, $75 \%$ of the 650,000 annual cases present late, at younger ages and about 510,000 deaths occur (Ngoma, 2006). The incidence ranges from 70/100,000 to- 100/100,000 people. Infectious agents like Hepatitis B, C, Human Papilloma Virus (HPV), Helicobacter pylori contribute significantly to cancers in developing countries. The HIV pandemic is changing the pattern and prevalence of cancer especially in East Africa where AIDS-related cancers like Kaposi sarcoma, lymphomas, anal cancers and cervical cancers are increasing (Parkin, 2003). Kaposi sarcoma (15.5\%) is now the commonest cancer of men in sub-Saharan Africa and cervical cancer (22.2\%) is commonest in women (Ngoma, 2006). 
The World Health Organisation has developed guidelines for regional and national cancer control programs according to national economic development. In its 58th World Health Assembly in 2005, the World Health Organisation urged member states to develop and reinforce comprehensive and evidencebased cancer control programs in order to curb the growing global burden of cancer.

It might seem that cancer registration should not be regarded as a priority for the health services of a developing country, given all the competing demands upon the limited resources allocated to health. However, cancer is already a significant health problem in many developing countries. More than half of the new cancer cases in the world occur in developing countries (Parkin et al., 1993). The rapid increase in life expectancy (largely because of a reduction in mortality from infectious disease) together with the adoption of western lifestyles suggests that the burden of cancer in these countries is likely to increase in the near future.

Most often cancer registries provide the only opportunity of properly assessing the extent and nature of the cancer burden in developing countries, since very few of them have reliable cause-specific mortality data. Ideally, the objective should be to establish a population-based cancer registry which will be able to estimate the incidence of different tumours in a well-defined community. However, because of the relative ease with which they can be established, cancer registries in developing countries often start on the basis of cases attending certain hospitals or departments of histopathology. Population-based cancer registries in developing countries usually face enormous logistic problems due to lack of appropriately trained personnel and adequate resources. In addition, their success may be jeopardized by external factors beyond their control.

\section{Methodology}

The system was developed using web-based technologies like HTML5 and Cascading Styling Sheets (CSS3) for the styles of the pages designed, these were used for the front end design of the cancer registry. The geographical distribution of cancer was made available using the Google Map Maker. Finally, the prototype system was developed using WAMP (Web-Apache-MySQL-PHP) server software through localhosting services. The spatial features introduced through Google Map was incorporated into the system using PHP and HTML.

WampServer was used to write MySQL queries for populating the database. The prototype was implemented using Adobe Dreamweaver; Apache was used as the web server to provide the basic functionality of the monitoring system. PHP was used as a scripting language to program the server-side manipulation of the knowledge in the database.

\section{Prototype Implementation}

The user interface allows the user to navigate the system and also facilitate interact with the database. The system is simple and user friendly through the use of Windows Interface Menu (WIMP), and pointing devices which is very important in computer graphics design and architecture. Hence, the online spatial

cancer registry for Nigeria was designed to accommodate health officers and policy officers with varying skills. A well designed and simple user interface provides user with a better understanding of the system. 
Adebayo Peter Idowu, Kehinde Oladipo Williams, Bunmi Alonge and Olusegun Ajibola Sarumi; Online Spatial Cancer Registry System for Nigeria. Journal of Biomedical Engineering and Medical Imaging, Volume 2, No 5, October (2015) , pp 10-20

\subsection{The home page module}

The home page is the first interface that the user views the moment the universal resource locator (URL) of the cancer registry is accessed (see figure 1). The home page is where the user can be able to access the buttons to navigate to every other part of the registry. For all registered users who want to perform any activity on the system, the user must click on the menu button (login) in order to log in and perform any necessary functions required.

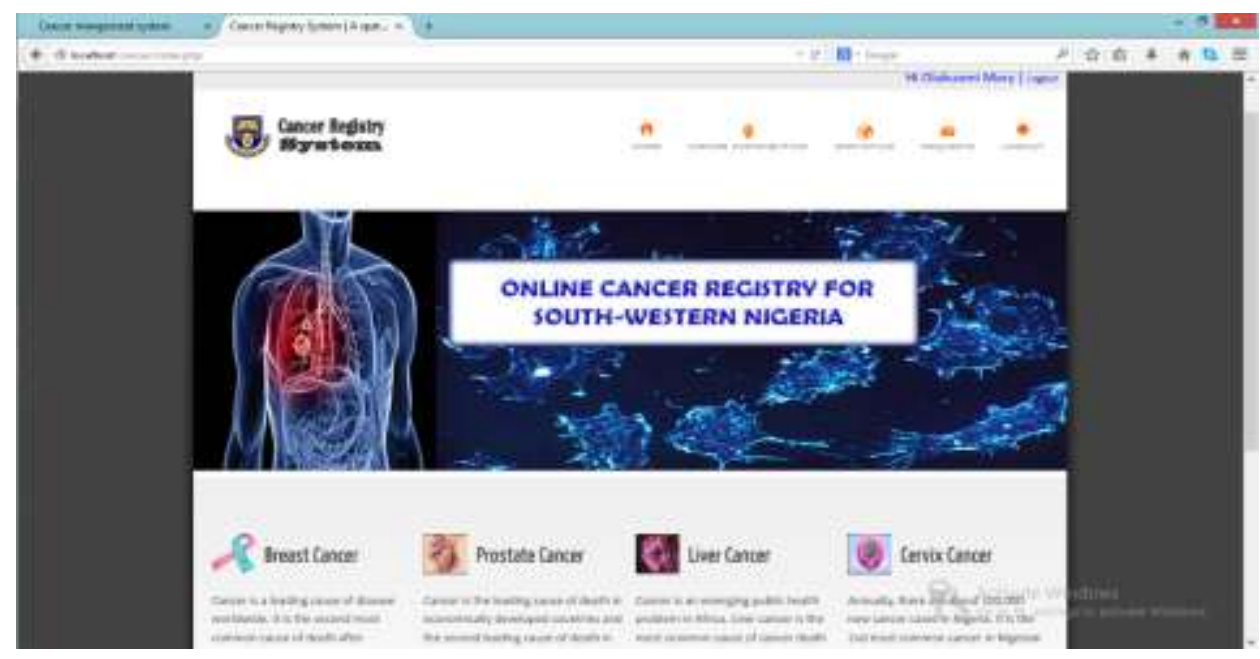

Figure 1: Home Page Module

\subsection{The user registration module}

User registration module is the module which allows all the users to send registration request to the admin (in this case the Registrar) by entering their personal details and necessary identifications indicating the type or category of user they belong to. In this module, each user is required to enter their name(s), username, password, e-mail address, agency/hospital name, user type, identification type, identification image and passport. The user then waits for his or her request to be approved by the registrar of the cancer registry. Figure 2 depicts the user registration module.

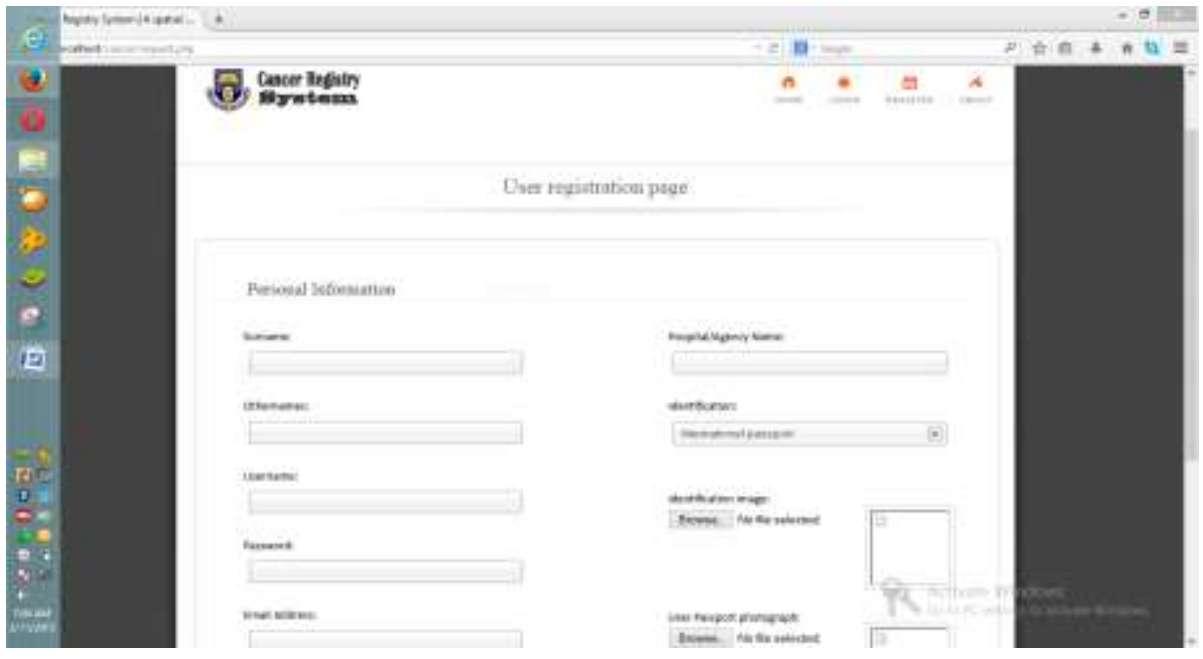

Figure 2: User Registration Module 


\subsection{The login module}

This module is the module that enables the approved users of the cancer registry to log in to the registry to perform all authorised activities within the jurisdiction of their user type. This module has the username, password and user type boxes. It also has a provision for the users that are yet to be registered to do so. The login module is depicted in figure 3.

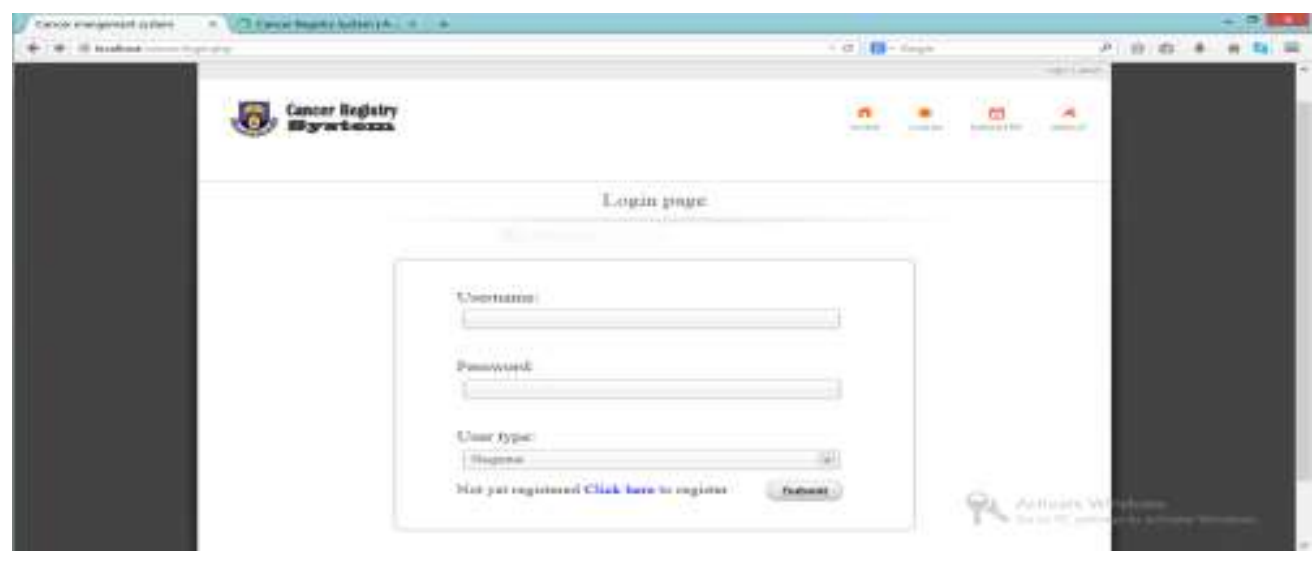

Figure 3: Login Module

\subsection{The cancer distribution module}

The cancer distribution module is simply the geographical display of the spread of cancer in a map of the area of study. It displays the various towns in south-western Nigeria that have any record of persons living with cancer and the types of cancer registered in the database of the cancer registry. The cancer distribution module can only be functional or available as long as there is internet connection on the device being used to access the cancer registry. All authorised users of the cancer registry can access this module. See figure 4 for the cancer distribution module.

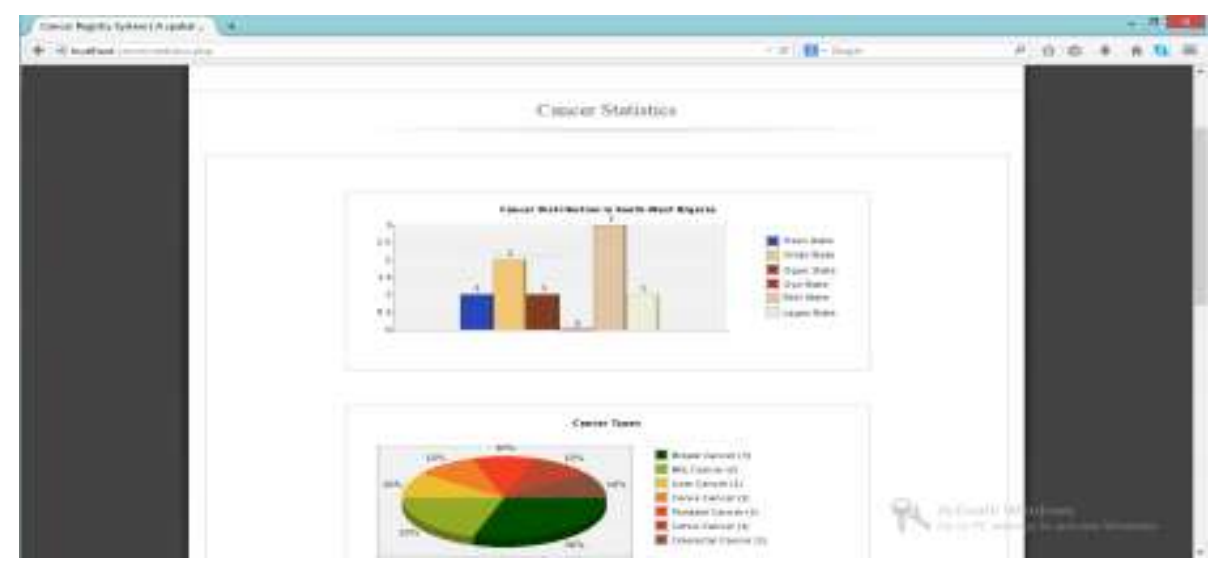

Figure 4: Cancer Distribution Module

\subsection{The registration requests module}

This module is the module that is accessed only by the registrar or any other authorised personnel of the cancer registry; this module enables the approval of the request sent in by anyone registering to become a user of the system. The registration requests module consist the user ID, names of the users, the 
Adebayo Peter Idowu, Kehinde Oladipo Williams, Bunmi Alonge and Olusegun Ajibola Sarumi; Online Spatial Cancer Registry System for Nigeria. Journal of Biomedical Engineering and Medical Imaging, Volume 2, No 5, October (2015) , pp 10-20

username, the user type, the hospital or organization name, the date of registration, the registration status of the user, action performed by the registrar. See figure 4 for the registration requests module.

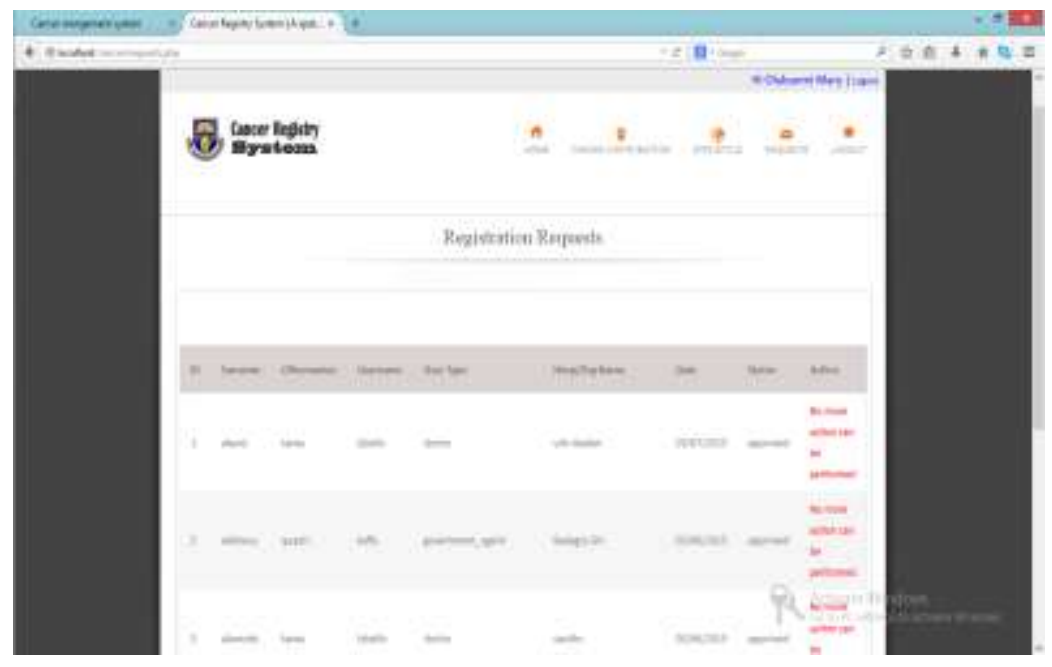

Figure 5: Registration Request Module

\subsection{The cancer distribution module}

The cancer distribution module is simply the geographical display of the spread of cancer in a map of the area of study. The map as shown in figure 4 displays the various towns in south-western states of Nigeria that have any record of persons living with cancer and the types of cancer registered in the database of the cancer registry. The cancer distribution module can only be functional or available as long as there is internet connection on the device being used to access the cancer registry. All authorised users of the cancer registry can access this module.

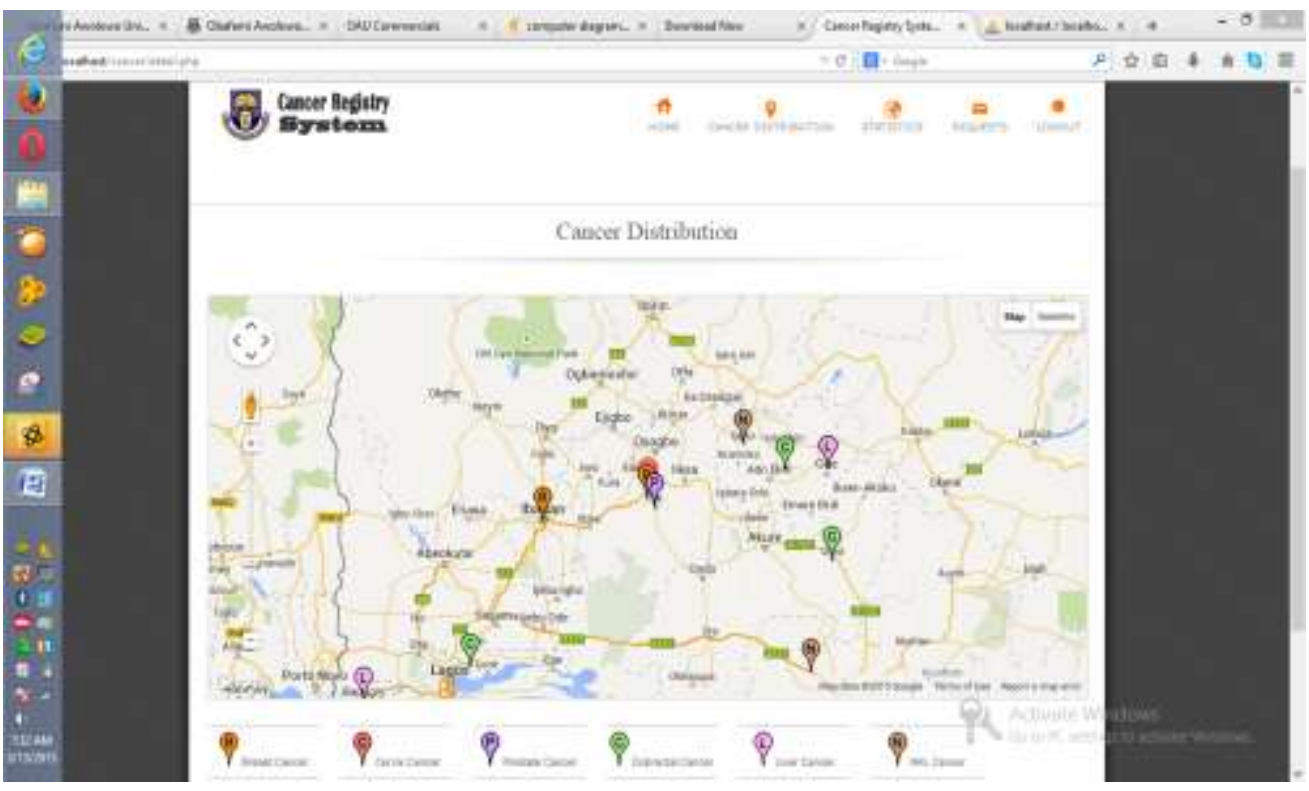

Figure 6 Cancer Distribution Module 


\subsection{Discussion}

The cancer registry information system was developed using the adopted data model to gather information comprehensively about cancer patients which will help monitor and control the widespread of the disease and provide a database for south-western Nigeria for monitoring and controlling of cancer and tumours generally. This will also help in determining the distribution rate of cancer in south-western Nigeria and the prevalence rate of cancer in this region of the country. The proposed system allows for the users to register information, view cancer statistics and cancer distribution in different towns of southwest in Nigeria based on their user type.

The project work makes use of bar charts, pie chart and map in order to allow for easy to understand and easy-to-interpret information view. Users can view cancer distribution details of any location on the map within the area of study with ease. This will help policy makers in making decisions regarding building cancer related health facilities and distribution of cancer equipment. The model in future may give arise to a comprehensive cancer registry for Nigeria as a whole. Also, oncologists, policy makers, and any other authorised users would be able to query, analyse, view and generate cancer distribution information based on cancer types, town/city and state level and this will enhance proper and wide cancer prevention awareness campaign.

This system will hopefully aid effective and efficient intervention in the rate at which cancer is claiming lives of Nigerians. This will improve the standard of health care system especially those related to cancer and tumours generally. This system will also serve as a way of having uninterrupted access to genuine information on cancer distribution (either hard copy or on the internet) in the nation.

\section{Conclusion}

This paper focuses on GIS based cancer population registry for Nigeria; it will indeed serve as reliable information storage and retrieval system of cancer incidence in Nigeria. The system testing showed the effectiveness and user-friendliness of the system in terms of information storage and retrieval time, the cancer distribution display on the map and the graphical user interface design. The system was designed and developed to capture cancer patient's information such as the name, gender, occupation, marital status, ethnicity, cancer type, cancer level, nationality, residential address, state of origin etc.

The system can display the cancer distribution of the various types of cancer in various locations on the map in terms of residential address of the patients. It is also able to display the cancer statistic in terms of gender, state, ethnicity and cancer types. The system will go a very long way in helping government and non-governmental agencies (NGOs) in providing necessary, proper and adequate cancer health care facilities in the nation that help improve the life of people living with cancer as well as prevent the death of citizens through early diagnosing and treatment. It will also enhance the channelling of campaigns on how to combat cancer to the right areas in the nation.

\section{REFERENCES}

[1] Abioye AA(1981), The Ibadan Cancer Registry. 1960-1980: Cancer in Africa proceedings of a workshop of the West African College of Physicians: Monrovia, Liberia: 6th-9th July, 1981. 
Adebayo Peter Idowu, Kehinde Oladipo Williams, Bunmi Alonge and Olusegun Ajibola Sarumi; Online Spatial Cancer Registry System for Nigeria. Journal of Biomedical Engineering and Medical Imaging, Volume 2, No 5, October (2015) , pp 10-20

[2] American Cancer Society (2008). Cervical Cancer. Available from www.cancer.org [Accessed July $17,2014]$

[3] Ananya Mandal, MD (2012) Cancer Symptoms News-Medical. Available from http://www.news-medical.net/health/Cancer-Symptoms.aspx [ Accessed December 2, 2014]

[4] Ananya Mandal, MD (2012) Cancer Classification. News-Medical Available from http://www.news-medical.net/health/Cancer-Classification.aspx [Accessed December 2, 2014]

[5] Awodele, O., Adeyomoye, A.A., Awodele, D.F., Fayankinnu, V.B., and Dolapo, D.C. (2011). Cancer distribution pattern in southwestern Nigeria. Tanzania Journal of Health Res., 13(2), 106108.

[6] CancerCare (2014). Lung Cancer 101. Available from www.lungcancer.org [Accessed March 7, 2015]

[7] Peter A. Dervan (1999). Understanding Cancer: A Scientific and Clinical Guide for the Layperson. ISBN 0-7864-0628-3 McFarlansd \& Company, Inc., Publisher

[8] Dewane JS, and Pandit VA.(2012). Understanding Redox Homeostasis and its Role in Cancer. Journal of Clinical and Diagnostic Research, 6(10):1796-1802.

[9] GLOBOCAN (2012). Estimated Cancer Incidence, Mortality and Prevalence Worldwide in 2112. Available from http://globocan.iarc.fr/Default.aspx [Accessed March 14, 2015]

[10] International Agency for Research on Cancer (2014). Making the population-based cancer registry. Planning and Developing Population Based Cancer registration in Low and MiddleIncome Settings, IARC Technical Publications Available from http://www.iarc.fr/en/publications/pdfs-online/treport-pub/treport-pub43/ [Accessed March 7, 2015]

[11] Kainsa et al (2012). Medicinal Plants of Asian Origin having Anticancer Potential: Short Review. Asian Journal of Biomedical and Pharmaceutical Sciences. 2(10)

[12] Moore, D. A., and Carpenter, T. E. (1999). Spatial Analytical Methods and Geographic Information Systems: Use in Health Research and Epidemiology. Epidemiologic Review, 21(2), 143-161

[13] National Cancer Institute (2003). Cancer and the Environment: What you need to know, what you can do. Available from http://www.niehs.nih.gov/health/materials/cancer and the environment 508.pdf [Accessed March 12, 2015] 
[14] National Cancer Institute (2008). National Cancer Institute, Where can I find Cancer Incidence Statistics? Available from http://surveillance.cancer.gov/statistics/types/incidence.html [Accessed March 12, 2015]

[15] National Cancer Institute (2014). Stomach Cancer. Available from http://www.cancer.gov/researchandfunding/snapshots/stomach [Accessed January 12, 2015]

[16] National Cancer Registry Association (2014). The Cancer Registry and the Registrar. Available from http://www.ncra-usa.org/i4a/pages/index.cfm?pageid=3862 [Accessed January 25, 2015]

[17] Ngoma, T. (2006). World Health Organisation. Cancer Priorities in Developing Countries. Annals of Oncology, 17: $9-14$.

[18] Parkin D.M (2013). Cancer Registration in Emerging Health Systems: The INCTR Cancer Registry Programme Available from http://cancercontrol.info/wpcontent/uploads/2014/08/cc2013 55-59-Maxwell-Parkin-incl-T-page 2013.pdf [Accessed February 16, 2015]

[19] Parkin D.M (2008). The role of Cancer registries in cancer control. Int. Journal of Clinical Oncol.; 13(2): 102-105

[20] Parkin D. M., Bray F. I., Devesa S. S. (2003) Cancer Burden in the year 2000-The global picture. European Journal of Cancer, S4-S66

[21] World Cancer Factsheet (2014). World Cancer Burden. Available from http://publications.cancerresearchuk.org/downloads/product/CS REPORT WORLD.pdf [Accessed March 18, 2015]

[22] World Health Organization (2006). Cancer control: knowledge into action: WHO guide for effective programmes. Geneva, Switzerland.

[23] World Health Organization (2008). World Health Statistics. WHO, Geneva.

[24] World Health Organization (2009). Cancer. Available from http://www.who.int/mediacentre/factsheets/fs297/en/index.html [Acessed December 21, 2014] 